\title{
The Victorian Early Years Learning and Development Framework: Managing change in a complex environment
}

\author{
Susanne Garvis \\ Donna Pendergast \\ Danielle Twigg \\ Bev Flückiger \\ Harry Kanasa \\ Griffith University
}

\author{
Carmel Phillips \\ Maggie Bishop \\ Kerryn Lockett \\ Victorian Curriculum and \\ Assessment Authority \\ (VCAA)
}

\author{
Darlene Leach \\ Victorian Department of Education \\ and Early Childhood Development \\ (DEECD)
}

THIS ARTICLE REPORTS ON an Educational Change Model originally developed for the middle years of schooling (Pendergast et al., 2005) and applied here to an Australian early childhood education reform initiative. The Victorian Early Years Learning and Development Framework (VEYLDF) was released in 2009 (DEECD \& VCAA, 2009). Implementation of the VEYLDF was accompanied by a three-stage independent evaluation on early childhood professionals perceptions of implementation. According to the Educational Change Model, three distinct phases can be identified as individuals and groups move towards full implementation of reforms. The phases are: Initiation, Development, and Consolidation.

Evaluation of initiatives delivered in the implementation of the VEYLDF against key elements of the Educational Change Model revealed that: critical model elements of visioning, policy development, stakeholder engagement and information dissemination were achieved at a high level; resources were developed for early childhood professionals to implement in a range of formats and mediums; the importance of leadership in educational change was recognised in the VEYLDF implementation; inhibitors and enablers to the implementation of the VEYLDF were identified in anticipation of the Development phase of the Educational Change Model.

- The staged implementation of the VEYLDF provided opportunities for progressive feedback on implementation successes and challenges.

\section{Introduction}

The Victorian Early Years Learning and Development Framework: For all children from birth to eight years (VEYLDF) was released in November 2009 (DEECD \& VCAA, 2009) for implementation from 2010. The VEYLDF aligns with Being, Belonging and Becoming: The Early Years Learning Framework for Australia (EYLF) (DEEWR, 2009), and links to the Victorian Essential Learning Standards (VCAA, 2005) in the early years of schooling. My time, our place-Framework for school age care in Australia (DEEWR, 2011) builds on the EYLF and extends the principles, practice and outcomes to accommodate the contexts and age range of the children and young people who attend school-age care settings.

The implementation of the VEYLDF is a partnership between the Policy and Strategic Projects Division, Department of Education and Early Childhood Development (DEECD) and the Early Years Unit, Victorian Curriculum and Assessment Authority (VCAA). Implementation of the VEYLDF requires significant cultural change amongst all early childhood professionals. This is occurring within two key reforms: Council of Australian Governments (COAG) reform in early childhood and in the development of an Australian curriculum for the school sector.

The National Quality Framework for Early Childhood Education and Care (NOF) commenced in January 2012. It is linked to national learning frameworks that recognise that children learn from birth. In combination, these frameworks outline fundamental components to inform and guide early childhood professionals in the delivery of nationally consistent and high-quality experiences and programs across Australia.

The development of the new Australian curriculum has a focus on general capabilities and cross-curriculum priorities. This reflects the integrated nature of children's learning in both the EYLF, the VEYLDF and in the Framework for School Aged Care in Australia. 
The VEYLDF advances all children's learning and development from birth to eight years. It does this by supporting all early childhood professionals to work together and with families to achieve common outcomes for all children.

\section{Evaluation}

Staff members from the School of Education and Professional Studies at Griffith University were commissioned by the VCAA to conduct an independent state-wide process evaluation of early childhood professionals' perceptions of the implementation of the VEYLDF in 2010-2011.

This paper reports on a snapshot of these findings in relation to the Educational Change Model. This model is helpful in understanding three phases of change that relate to early years reform. Each phase-Initiation, Development, and Consolidation-describe indicative levels of engagement and suggest strategies for ongoing professional learning.

\section{Theoretical framework}

The evaluation was guided by research, in particular the Educational Change Model (the Model) originally developed for reform processes in Australian middle schooling (Pendergast et al., 2005; Pendergast, 2006). This Model has been drawn from an educational scenario; however the principles underpinning the reform model are equally applicable to business, industry and community reform settings. The Model has value for an individual, for a site or setting, and at a systemic level. At the individual level it can be used to assist a person to determine the stage of reform at which they are operating by reflecting on their understandings and practices. Similarly, in a specific site the phase of reform can be determined by auditing the evidence presented across the site. At a systemic level the guidance required to scaffold individuals and sites to achieve reform can be tailored by utilising the components of the phases as an audit tool. Hence, the adoption of the Model is applicable to the innovative change in early childhood reform in this project.

The Model (see Figure 1) proposes that programs of reform are typically established in three phases, gradually introducing particular core component changes, and spanning a total of about eight to 17 years, depending on circumstances. The Model and the relevant literature also recognise that educational reform takes longer than usually expected or normally allowed for in reform schedules. A guiding principle of the Model is the importance of developing 'lifelong learning' for both children and early childhood professionals; a principle that is also central to the VEYLDF.

The three broad phases can be mapped into any major reform initiative, and features indications of time taken to achieve each phase (see Figure 2). The Initiation phase typically occupies the first year or two; the Development phase typically spans the next two to five years; and the Consolidation phase can last over a further five to 10 years. The periods associated with each of the three phases are indicative only and can be accelerated through the alignment of enablers. Similarly, inhibitors can lead to dips in the reform program, adding extra time to the overall reform process.

During the Initiation phase reforming organisations are characterised by activities that include goal setting (for example, development of vision statements), and developing buy-in and information dissemination of the new reforms, what they entail and how they'll be achieved (Pendergast, 2006). The focus for individuals is on understanding the new reforms and the implications for changes to their thinking, language and practices. The Initiation phase typically extends from one to two years.

During the Development phase, typically from years two-five, individuals and groups are deepening their understanding of the reforms, and implementing more and more new practices in accordance with the new reforms. This stage of exploration and experimentation yields many successes, but inevitably leads to some failed trials and experiments. This can sometimes result in frustration, despair and despondency with the new reforms and is accompanied by decreases in performance and perceived efficacy. This is identified in the literature as an implementation dip (Pendergast \& Main, 2011).

Factors which cause, exacerbate and/or lengthen the dip are known as 'inhibitors', while 'enablers' are factors which aid effective implementation and shorten the dip. Pendergast et al. (2005) identified 13 inhibitors of reform in educational settings ranging from weak or inconsistent leadership to poorly conceived vision statements; from insufficient funding to resistance from the community. Typically the organisational focus starts to turn away from the reform efforts with a corresponding reduction in funding. Sustained commitment beyond the life of the initial reform notification is required to ensure continuity of focus.

During the Consolidation phase, typically from years five-10, individual and group understanding of the reform is much more closely aligned and practices have been largely bedded down. Organisations are further deepening their knowledge, and the language and practices are becoming more automatic and widespread within the organisation. Individual reliance on experts and leadership decreases as their own expertise increases. Reform efforts have largely disappeared by this phase with the expectation that individuals are able to continuously improve independent of external assistance as individuals move towards a more expert knowledge and practice base.

As individuals and groups progress along their reform trajectory their understanding and ability to implement the reform changes over time. Because of these changes the implementation activities must conform to the needs of 
Figure 1. The Educational Change Model

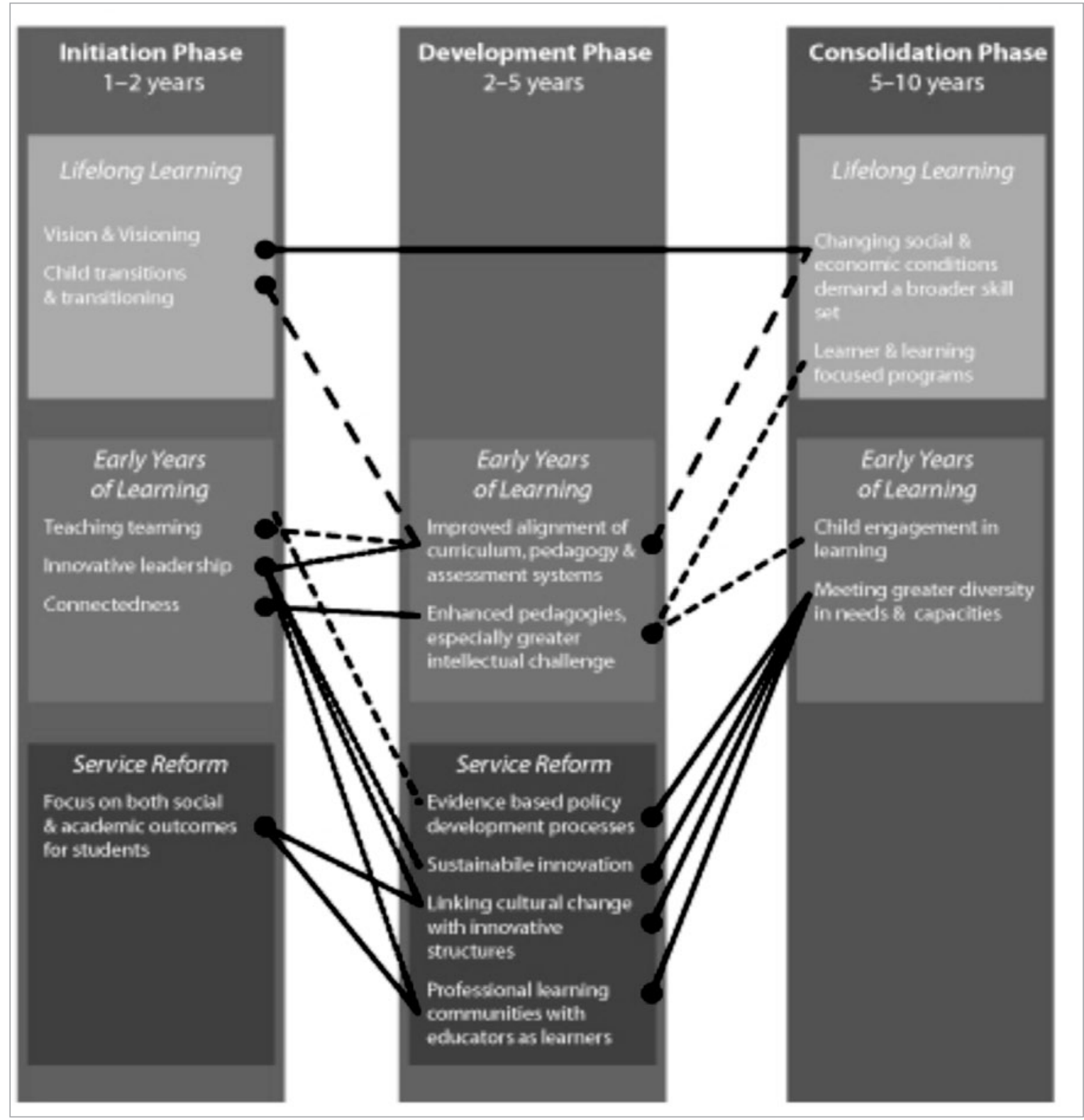

the group during that particular phase. The more closely aligned the activities are with the needs of the individual, the more likely, and sooner, they move towards full implementation.

An important dynamic presented in Figure 2 is the varied response to introducing change. There is a widespread myth that performance will automatically improve in response to change (the dotted line), when in fact actual performance generally experiences a dip following the introduction of change or reform. Applying appropriate recommendations can reduce the depth of the decline and also reduce the duration of recovery.

This is very important when applied to early childhood implementation initiatives, where a diverse sector is coming together, finding a new voice and beginning discussion about pedagogy competence. The transition from Initiation to Development can often involve a drop in confidence and a loss of momentum. 
Figure 2. The Educational Change Model mapped against a typical reform curve

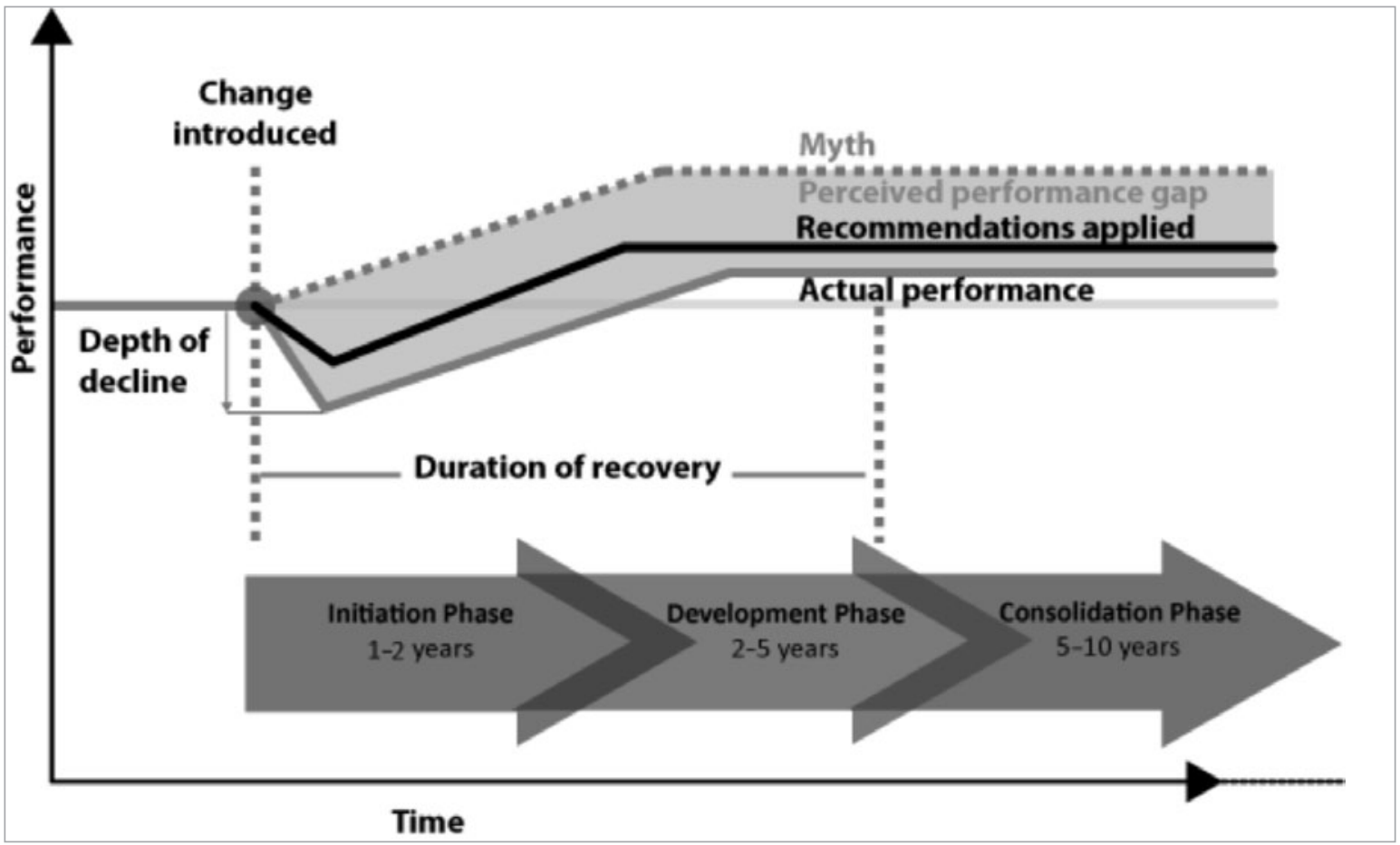

As Pendergast et al. (2005, p. 85) note:

Even with dynamic and consistent leadership ... the effort required to maintain the momentum of reform is enormous, and it is not uncommon for enthusiasm to wane, especially if funding is not sufficient to meet adequately all of the very high costs usually associated with the quality of renewal required. Most ... in the Development phase undergo a significant 'dip' in their implementation efforts and the efficiency with which they are able to operate.

This 'typical pattern' can be represented diagrammatically as in Figure 3.

Figure 3. A 'typical' implementation trajectory in a reforming school

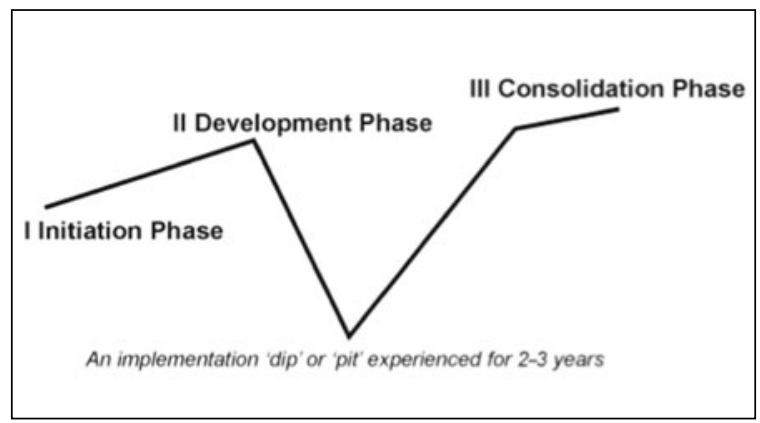

Pendergast et al. (2005) also note that it is possible to move from the typical trajectory and facilitate a smoother transition in the reform process by actively pursuing a program that optimises 'fast track' conditions. Research in the school sector indicates that for some reforming schools (or indeed elements within a single school site) the implementation experience is often less traumatic, and early childhood professionals can experience smoother sailing. Usually this can occur only when several key factors are aligned and sustained:

- Team membership across several years.

- Congenial, philosophically-aligned dynamics among team members.

- Sensitive and sustained leadership.

- Early adoption and shared risk-taking among members who challenge each other to extend themselves.

- A strong emphasis on team problem posing and problem solving.

- Effective use of research in evidence-based planning. Under these optimal 'fast track' conditions the pattern may look more like that illustrated in Figure 4. 
Figure 4. A 'fast track' implementation trajectory in a reforming school

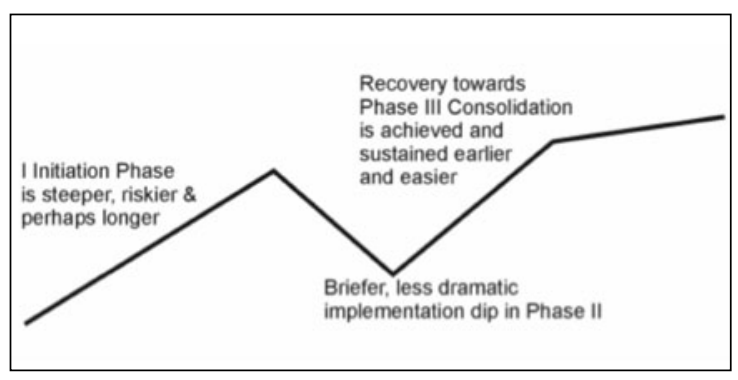

The staged implementation of the VEYLDF can be mapped to/overlaid with the Model, as can be seen in Figure 2, with initiatives throughout 2010-2011 corresponding to the Initiation phase of the Model.

\section{Implementation of the VEYLDF}

In the first stage of implementation the VCAA and DEECD provided a range of implementation activities and resources to support early childhood professionals in getting started with the VEYLDF. The implementation of the VEYLDF used a staged approach and additional resources, and activities are being developed and released over time.
Table 1 summarises these activities and resources scheduled from the commencement of the evaluation process in July 2010.

The implementation of the VEYLDF required significant cultural change for all early childhood professionals. It was the first time the Learning and Development Outcomes and Practice Principles for Learning and Development had been articulated. It is also the first time all early childhood professionals have been brought together across the birth to eight years period; with a common framework to advance children's learning and development.

A detailed description of each activity and resource is provided in Appendix 1. A key element of the evaluation process was to determine whether the activities and resources provided were utilised, and their value to early childhood professionals (Garvis et al., 2011). Engagement and buy-in are critical aspects of the initiation phase in the Model. As noted by Hall and Hord (2001), a lack of motivation to use implementation activities as designed may adversely impact on the level of engagement, limiting it to a mechanical level. Other possible barriers to implementation at this critical first stage include a lack of knowledge of the change process (Easton, 2008) and non-involvement or lack of interest by key stakeholders (Stoll \& Fink, 1996).

Table 1. A list of the online and face-to-face implementation activities and resources as at July 2011

\section{\begin{tabular}{|l|l|} 
Online activities and resources & Face-to-face activities and resources
\end{tabular}}

VCAA Early Years Exchange (the EYE) Editions 1-6 2010 Early Childhood Education Conference (hosted by KPV and December 2009 to June 2010

Gowrie Victoria) June

Early Years Alert-online publication through VCAA Regional information sessions 2010

PowerPoint Presentation to Families on the VEYLDF Bastow Institute: Leading People in Early Childhood Settings, April March 2010 to July 2010 and March to August 2011

2010 Early Childhood Education Conference (KPV/ Bastow Institute: Educational Leadership in Early Childhood Settings Gowrie) Online Papers available from June 2010

May to June 2010 and May to August 2011

The Learning and Development Outcomes from the Statewide Module 1-An Introduction to the VEYLDF and Reflective VEYLDF linked to the Victorian Essential Learning Practice delivered between May 2010 and June 2011

Standards (VELS) July 2010

Online Module 1. An Introduction to the Victorian Statewide Module 2-An Introduction to Collaborative Practice Framework and Reflective Practice published delivered between May 2010 and June 2011

October 2010

Online Module 2. An Introduction to Collaborative Practice published October 2010

Statewide Module 3-An introduction to Effective Practice delivered between May 2010 and June 2011

Evidence Paper Practice Principle 8: Reflective Statewide Module 4-Assessment for Learning and Development: Practice published October 2010

The Early Years Planning Cycle delivered between May 2010 and June 2011

Online Module 3. An Introduction to Effective Bastow Institute: Contemporary Child Development Theory for Early Practice published April 2011 Childhood Educators July to December 2010

2011 Early Childhood Education Conference (KPV/ VCAA Learning and Development Outcomes Project July 2010 to Gowrie) Online Papers available from June 2011 June 2011 Victorian Early Years Coaching Program October 2010 to December 2011 


\section{Evaluation methodology}

The aims of the evaluation were to measure and report on the early childhood professionals' perceptions of reach and engagement of the implementation of the VEYLDF; to identify enablers, inhibitors and barriers experienced by early childhood professionals; and to identify emerging leadership. This can be discussed in terms of the Educational Change Model. The evaluation consisted of a survey in Stage 1, indepth interviews in Stage 2, and a second survey in Stage 3.

\section{Stage 1 survey}

Participants were recruited by communications with DEECD regional staff and through email, letters and phone calls. Further information about the survey is available in the final report. The online survey was open from 5 October, 2010-14 December, 2010. Of the 405 fully completed responses to the survey, the majority (92 per cent) completed the online version.

\section{Stage 2 semi-structured interviews}

Twenty participants were recruited from each DEECD region in Victoria using stratified sampling. Stratification was based on geographic location, early childhood service, role in the service, years of experience and the age of the children the participant worked with. Stratification also represented community, and public and private early childhood services. Participants were selected from a list generated from the Stage 1 survey, based on self-nomination and recommendations by DEECD staff in regional offices. The 20 in-depth interviews were conducted by the Griffith University team during March 2011. One of the limitations of the interview was that it was self-reported data.

\section{Stage 3 survey}

The Stage 3 survey was conducted from 18 July-15 August 2011 to identify change and difference and emerging leadership as a result of accessing implementation activities so far. The survey was completed by 736 early childhood professionals following the same sampling methodology used in Survey 1.

Overall, the self-reported profile of the 1,141 respondents to the two surveys and the 20 interviewees was:

- The majority aged 40 years and above.

- Had more than 10 years experience.

- Had a Bachelor degree.

- Worked within the universal services sector (37 per cent in kindergarten).

- Worked with children aged three to five years.

The findings in this study provide a snapshot of the early childhood profession in Victoria. Data was analysed through statistical and content analysis. As it is self-reported data, it is limited in its ability to generalise the entire profession.

\section{Implementation of the VEYLDF mapped to the Educational Change Model}

A theoretical model was necessary to understand the educational change taking place in the early childhood profession. The Educational Change Model was used to understand the extent of change following the implementation of the VEYLDF. The model was used to map each phase of change. Table 2 presents a summary of key Model elements for each of the three reform phases.

Table 2. Key elements of the Model for each phase of reform

\begin{tabular}{|c|c|c|}
\hline Initiation Phase 1-2 years & Development Phase 2-5 years & $\begin{array}{l}\text { Consolidation Phase 5-10 } \\
\text { years }\end{array}$ \\
\hline $\begin{array}{l}\text { Model elements } \\
\text { Goal setting } \\
\text { Visioning } \\
\text { Transitions and transitioning processes } \\
\text { Developing buy-in } \\
\text { Information dissemination } \\
\text { Understanding new reforms } \\
\text { Implications for change } \\
\text { Innovative leadership } \\
\text { Auditing }\end{array}$ & $\begin{array}{l}\text { Model elements } \\
\text { Improved alignment of curriculum, } \\
\text { pedagogy and assessment systems } \\
\text { Sustainable innovations } \\
\text { Enhanced pedagogies, especially } \\
\text { the provision of greater intellectual } \\
\text { challenge } \\
\text { Professional learning communities, } \\
\text { with early childhood professionals as } \\
\text { learners } \\
\text { Evidence-based policy development }\end{array}$ & $\begin{array}{l}\text { Model elements } \\
\text { Changing social and economic } \\
\text { conditions demanding a broader } \\
\text { skill set } \\
\text { Learner- and learning-focused } \\
\text { programs } \\
\text { Child engagement in learning } \\
\text { Meeting greater diversity in child } \\
\text { needs and capabilities }\end{array}$ \\
\hline $\begin{array}{l}\text { Framework elements } \\
\text { Visioning } \\
\text { Policy } \\
\text { Resource creation } \\
\text { Information dissemination } \\
\text { Professional learning opportunities } \\
\text { Independent evaluation } \\
\text { Early identification of Enablers and Inhibitors }\end{array}$ & $\begin{array}{l}\text { Framework elements } \\
\text { To be developed from evaluation } \\
\text { findings, consultation with key } \\
\text { stakeholders, alignment with elements } \\
\text { of the educational change model and } \\
\text { current education literature }\end{array}$ & $\begin{array}{l}\text { Framework elements } \\
\text { To be developed from evaluation } \\
\text { findings, consultation with key } \\
\text { stakeholders, alignment with } \\
\text { elements of the educational } \\
\text { change model and current } \\
\text { education literature }\end{array}$ \\
\hline
\end{tabular}


Evaluation findings show that, in the implementation of the VEYLDF, key model elements in the Initiation phasevisioning, policy development, resource creation, stakeholder engagement and information dissemination-were achieved at a high level. Evidence of this achievement includes:

- Development of policy documents that align and complement other state and national early childhood educational frameworks and initiatives.

- Development of a wide range of implementation activities and resources for early childhood professionals to assist with introducing the VEYLDF. These included online and face-to-face initiatives.

- Evaluation findings that 94 per cent of Survey 1 and 96 per cent of Survey 2 respondents had accessed at least one implementation resource and/or activity.

- The evaluation found that face-to-face opportunities to learn about the VEYLDF, network and discuss issues were especially valued when the content was specific to the participants' work setting. The most frequently attended face-to-face activities were the regional information sessions and the state-wide modules.

- VEYLDF information was widely disseminated. The majority of respondents in Survey 1 supported themselves in the implementation of the VEYLDF by reading publications and accessing websites related to the VEYLDF (68 per cent); by working in a team that was actively interested in the VEYLDF (65 per cent) or by working in a service where the culture supported the VEYLDF (50 per cent).

- In-depth interviews confirmed survey results that innovative leadership and collaborative learning environments are seen as important for successful implementation of the VEYLDF, especially the transition to the Development phase of the reform.

- Evaluation findings that many early childhood respondents rated themselves as highly confident and capable with the Learning and Development Outcomes and Practice Principles.

- Indications of practice change occurring as a result of the implementation process, with examples including changes in language use and thinking of and about the VEYLDF.

As part of the preparation for transition to the Development phase of the VEYLDF the evaluation identified the following enablers and inhibitors that might influence the implementation dip (Pendergast \& Main, 2011).

\section{Enablers}

Respondents valued professional development which is easily understood; practical; service-specific; and delivered by knowledgeable presenters.

An analysis of respondent comments about the type of implementation activities they had accessed revealed three common themes-early childhood professionals preferred professional learning which was delivered in language and terms they understood; offered practical advice and suggestions on how to implement the VEYLDF which was specific to their service; and sessions that were delivered by knowledgeable presenters.

The implementation activities most valued were small and localised. At these activities early childhood professionals were able to share, collaborate, discuss and reflect upon their own practice. Participants not only gained practical tips and reassurance but also were able to strengthen and form new professional networks. Many respondents were looking for resources, templates, proformas and 'practices that work' to be able to implement the VEYLDF and meet reporting requirements.

To follow up on professional learning, respondents overwhelmingly relied on formal (initiated by their service, regional office or industry body) and informal (initiated by individuals, across services) networking opportunities. Formal professional learning activities consisted of the four DEECD state-wide Modules that were delivered to all regions and multiple regional locations from 2010. The Modules were filmed and are now available online. These follow-up sessions are critical in terms of supporting and reassuring early childhood professionals as they progress towards implementing the VEYLDF.

\section{Inhibitors}

Access of early childhood professionals to implementation activities was restricted by time location, computer equipment, and availability and capacity to attend.

The existence of contextual barriers to change may limit opportunities for developing collaborative learning environments. Early childhood professionals in the interviews and surveys listed many contextual barriers that limited their opportunity to access implementation activities. For face-to-face activities, barriers included: timing of activities (unsuitable timing of activities); access to activities (limits on number of people who could attend); location (activities required the early childhood professional to travel to another location); and leadership self-selection process (Bastow Institute).

Identified contextual barriers for online resources included limited computer access, access to relief staff, time to log online, and access to reliable internet connections. Some early childhood professionals also listed their level of technical skill as a barrier to access.

\section{Leadership}

Initial glimpses of early childhood leadership started to emerge in the Initiation phase, with some early childhood professionals supporting and leading others in the implementation process. 
Sustained leadership and supportive networks are central to establishing and maintaining the conditions for effective implementation. Rogers (2003) suggests that an individual's interest or need governs the rate of implementation. In this Initiation phase some early childhood professionals noted examples of support and leadership from colleagues, representing an embedding of the implementation of the VEYLDF. In some early childhood services, time was allocated to staff to allow colleagues to deeply explore content within the VEYLDF together. This approach supported and enhanced staff relationship and knowledge-building about the VEYLDF that was then contextualised within the early childhood services. Early childhood professionals appeared to value opportunities for professional learning within their service.

\section{Recommendations}

According to the Model (Pendergast, 2006) it is possible to facilitate a smoother transition in the reform process by optimising 'fast track' conditions which include team building, strong leadership and effective use of research in evidence-based planning.

As the needs of early years professionals change as they move along their reform trajectory (for example, from the Initiation to Development phase) so must the type of support and activities change. This is identified as necessary by the Model and by respondent comments during the evaluation.

The recommendations within a reform trajectory of continuous improvement are:

1. That the findings of this evaluation are triangulated with other data sources to further inform future VEYLDF implementation planning. This would include but is not limited to the views of professional learning consultants, evidence from VEYLDF implementation inquiry projects, and data from the National Quality Framework.

2. To articulate the differences and similarities of the various legislated and regulated Frameworks (VEYLDF, EYLF, The Framework for School Aged Care in Australia and the NQF) and the Australian curriculum in schools (Initiation).

3. To facilitate professional learning activities and workshops that are large-scale (Initiation) and then follow up with smaller local networking opportunities (Development).

4. To coordinate with the larger services and industry bodies to organise localised and integrated professional learning that may include elements of support that are service specific. Support consultants and regional offices to deliver personalised mentoring and/or coaching for individual services (Development).
5. To stream workshops and seminars on the internet so early childhood professionals in regional and rural areas can meet at hubs to watch the broadcast (Initiation). This doubles as a networking opportunity (Development).

6. To create plain language materials about the VEYLDF that double as professional learning for staff and information for parents (Initiation and Development).

7. To create resources that demonstrate exemplar practices (Development).

8. To apply the Educational Change Model and continuous improvement theory; to support further progress within this period of implementation reform (Development).

\section{Conclusions}

This paper has reported on the Initiation phase of the Educational Change Model in relation to early childhood professionals perspectives of the implementation of the VEYLDF. The Model provides the opportunity to build in specific steps to support change. It provides a useful frame of reference to support early childhood professionals and emerging leaders to map progress at the individual, service level or network level within a frame of continuous improvement. Further information about the final report can be found at www.vcaa.vic.edu.au/Pages/earlyyears/ index.aspx.

\section{Acknowledgements}

This report is part of the independent evaluation of the Implementation of the Victorian Early Years Learning and Development Framework (Tender No. VCAA 09/10 - 032) commissioned by the Victorian Curriculum and Assessment Authority (VCAA). The evaluation team thanks Carmel Phillips, Kerryn Lockett, and Maggie Bishop from VCAA, and Darlene Leach, Kirsten Slape and Bridget Healey from the Department of Education and Early Childhood Development (DEECD) for their support, and also the many early childhood professionals state-wide who participated in the study. The team also acknowledges the work of Dr Jeff Wilks who acted as an external consultant to the project.

\section{References}

Department of Education, Employment and Workplace Relations (DEEWR). (2009). Being, belonging and becoming: The Early Years Learning Framework for Australia. Canberra: Council of Australian Governments.

Department of Education, Employment and Workplace Relations (DEEWR). (2009). National Quality Standard for early childhood education and care and school age care. Canberra: Council of Australian Governments. 
Department of Education, Employment and Workplace Relations (DEEWR). (2011). My time, our place: Framework for school age care in Australia. Canberra: Council of Australian Governments.

Easton, L. (2008). Context: Establishing the environment for professional development. In L. Easton (Ed), Powerful designs for professional learning (pp. 1-19). Oxford, OH: National Staff Development Council.

Final Report on the evaluation of the implementation of the Victorian Early Years Learning Framework. VCAA website: www.vcaa.vic.edu.au/pages/earlyyears/research.aspx

Garvis, S., Pendergast, D., Twigg, D., Flückiger, B., Dachs, T., \& Kanasa, H. (2011). Evaluation of the implementation of the Victorian Early Years Learning and Development Framework: For all children from birth to eight years. Interim report 9 May 2011. Southport: Griffith University Early Childhood Education Centre.

Hall, G. E., \& Hord, S. M. (2001). Implementing change: Patterns, principles and potholes. Boston: Allyn \& Bacon.

Pendergast, D., Flanagan, R., Land, R., Bahr, M., Mitchell, J., Weir, K., Noblett, G., Cain, M., Misich, T., Carrington, V., \& Smith, J. (2005). Developing lifelong learners in the middle years of schooling. A report about the practices, process, strategies and structures that best promote 'lifelong learning' and the development of 'lifelong learners' in the middle years of schooling. Brisbane, Queensland: The University of Queensland.
Pendergast, D. (2006). Fast-tracking middle schooling reform: A model for sustainability. Australian Journal of Middle Schooling, 6(2), 13-18.

Pendergast, D., \& Main, K. (2011). Middle school reform: Constructing an audit tool for practical purposes. Australian Journal of Middle Schooling, 11(2), 4-10.

Rogers, E. M. (2003). Diffusion of initiatives. (5th edn). New York, NY: Free Press.

Stoll, L., \& Fink, D. (1996). Changing our schools. Buckingham: Open University Press.

Victorian Curriculum and Assessment Authority (VCAA). (2005). Victorian essential learning standards: Overview. East Melbourne: DEECD.

Victorian Department of Education and Early Childhood Development (DEECD) \& Victorian Curriculum and Assessment Authority (VCAA). (2009). Victorian early years learning and development framework for all children from birth to eight years. East Melbourne: DEECD. 